\title{
Trajectory of COVID-19 Data in India: Investigation and Project Using Artificial Neural Network, Fuzzy Time Series and ARIMA Models
}

\author{
Pradeep Mishra $^{1^{*}}$, Chellai Fatih ${ }^{2}$, Deepa Rawat ${ }^{3}$, Saswati Sahu ${ }^{4}$, \\ Sagar Anand Pandey ${ }^{5}$, M. Ray ${ }^{6}$, Anurag Dubey ${ }^{7}$ and Olawale Monsur Sanusi ${ }^{7}$ \\ ${ }^{1}$ Department of Statistics, College of Agriculture, Powarkheda, JNKVV (M.P.), India. \\ ${ }^{2}$ Department of Based Education, University of Ferhat Abbas, Algeria. \\ ${ }^{3}$ College of Forestry, Ranichauri, Tehri Garhwal, VCSG UUHF (Uttarakhand), India. \\ ${ }^{4}$ West Bengal State University, W.B., India. \\ ${ }^{5}$ KVK, Bhatapara, IGKVV, Raipur, Chhattisgarh, India. \\ ${ }^{6}$ [RRTTS] (OUAT), Keonjhar, Odisha, 758002, India. \\ ${ }^{7}$ Laboratoire de Mécanique Gabriel Lamé (LaMé), INSA Centre Val de Loire, Blois, France.
}

Authors' contributions

This work was carried out in collaboration among all authors. Author PM, CF, DR and SS designed the study, performed the statistical analysis, wrote the protocol and wrote the first draft of the manuscript. Author SAP, MR, AD and OMS managed the analyses of the study. Authors AD and OMS managed the literature searches. All authors read and approved the final manuscript.

Article Information

DOI: $10.9734 / A R R B / 2020 / v 35 i 930270$ Editor(s):

(1) Dr. Bechan Sharma, University of Allahabad, India. (2) Dr. Layla Omran Elmajdoub, Misurata University, Libya. (3) Dr. Manikant Tripathi, Dr. Ram Manohar Lohia Avadh University, India

Reviewers:

(1) Mehdi Neshat, University of Adelaide, Australia. (2) PPG Dinesh Asanka, University of Moratuwa, Sri Lanka. (3) Wajid Aziz, University of Azad Jammu and Kashmir (UAJK), Pakistan. Complete Peer review History: http://www.sdiarticle4.com/review-history/60216

Original Research Article

Received 31 July 2020

Accepted 22 August 2020

Published 31 August 2020

\section{ABSTRACT}

Due to the impact of Corona virus (COVID-19) pandemic that exists today, all countries, national and international organizations are in a continuous effort to find efficient and accurate statistical models for forecasting the future pattern of COVID infection. Accurate forecasting should help governments to take decisive decisions to master the pandemic spread. In this article, we explored 
the COVID-19 database of India between 17th March to 1st July 2020, then we estimated two nonlinear time series models: Artificial Neural Network (ANN) and Fuzzy Time Series (FTS) by comparing them with ARIMA model. In terms of model adequacy, the FTS model out performs the ANN for the new cases and new deaths time series in India. We observed a short-term virus spread trend according to three forecasting models. Such findings help in more efficient preparation for the Indian health system.

Keywords: Artificial neural network; ARIMA; COVID-19 forecasting; fuzzy time series; India.

\section{INTRODUCTION}

The COVID-19 pandemic is the current global health crisisthat receives extraordinary supports and attention since World War II [1,2]. The COVID-19 cases initially observed in the Wuhan province of China are now immensely increasing around the world as a consequence of which the Government of India has called upon the powers under the Epidemic Diseases Act, 1897 to raise preparedness and containment of the virus and declared COVID-19 a 'notified disaster' under the Disaster Management Act 2005. On 24 March2020, the Government of India imposed nation wide lockdown for 21 days, which was further extended on 14 April and 01 May until 17 May, for preventive measure against the spread of COVID-19 in India.

In the third phase of lockdown, the Government divided the whole country into three different zones - Green, Red and Orange, with relaxations applicable accordingly. Government of India declared fourth lockdown from 18 May to 31 May, 2020. However, after all the lockdowns, cases were increasing day by day. Globally, $14,043,176$ confirmed cases were recorded till July 19, 2020 along with 597583 fatalities owing to the infections [3].In India, after June 8, a phase of reopening of economy started with Unlock 1 to revive economic growth which increased the caseload as the spread of infection peaked due to unlock and manifested into $1,188,223$ confirmed cases till July 20, 2020. But India is still at lower trajectory in case of deaths owing to COVID-19 compared to any other countries in the world due to recovery rate of 62.8 percent which points towards the fact that despite high population density and vulnerability towards community transmission, India has contained the transmission of virus to a great extent. Presently, total active cases in the country are 412,404 with 28,712 deaths. we have nearly same pattern over the provinces; Maharashtra, with 327,031 recorded cases and recovery rate of 54 percent is highest infected state of the country followed by Delhi, having
125,096 total cases with recovery rate of 71 percent at 20 July 2020 .

Considering the onset of infections in the country the Indian government quickly activated its health management system and issued necessary travel advisories, which included screening of all travelers coming into the country from COVID affected nations as early as January 2020. Theysetupinstitutional quarantine and isolation centers using government infrastructure, which ranged from schools, community centers, hotels to rail couches. Simultaneously, with increasing infections, Indian administration was forced to hastily scale-up its critical care infrastructure. According to health ministry of India, to fight against COVID-19, 32000 ventilators have been installed before March 30 , 2020.India with huge populating counties, the government had increased the spending upto 2.5 percent of GDP as compared to previous1.4 percent on public healthcare expenditure.

Meanwhile, several non-medical equipment companies in the country have also risen to the occasion and transformed their manufacturing lines to produce ventilators and other relate equipment. According to the Association of Indian Medical Device Industry, states had designated958 COVID hospitals across the country, as well as 2,313 COVID health centers for those who do not need too much medical support, and 7,525 COVID care centers for patients with mild infections who are unable to isolate themselves at home. Along with this, domestic manufacturers are providing enough medical devices, protective gear, diagnostics, hospital equipment, and telemedicine services to efficiently overcome the adversities of COVID pandemic in the second largest populated nation.

Time series forecasting models have great scope in present era especially in case of epidemic diseases projection. Researcher considered temporal dynamic for projection of COVID-19 on China, Italy and French [4]. Another study has forecasted the COVID-19 outbreak in Canada 
using the LSTM network[5]. For COVID-19 in India, forecasting has been done using the SIR and logistic model [6]. Another research teams used Exponential smoothing method [7] and [8] ARIMA models for forecasting purpose. Most recently, machine learning is a useful technique for forecasting purpose and researchers are using it in different fields of science. Machine learning models were compared with different forecasting models based on COVID-19 related data. It was found that the machine learning performance is better than other models. For few data, SVP performance was better than machine learning [9]. In another study, machine-learning techniques were used for projection of COVID-19 data in India[10]. In this present investigation, Artificial Neural Network, Fuzzy Time Series and ARIMA models were used for forecasting in COVID-19 data. The models were compared and the best forecasting models were identified for projection purpose in aiding proper planning to fight against this epidemic disease.

\section{MATERIALS AND METHODS}

The main goal of building of mathematical models in time series data is forecasting the future pattern and trajectory. The classical models such: Exponential smoothing [11], Autoregressive Integration Moving Average (ARIMA) [12],Kalman filter [13] are the main used in application. We focus mainly on two approaches, namely: Artificial Neural Network models $[14,15]$ and Fuzzy Time Series models (FTS) $[16,17]$ by comparing them with ARIMA technique. Both of ANN and FTS belong to the nonlinear time series models.

\subsection{Auto Regressive Integrated Moving Average (ARIMA)}

Given a time series of data $X_{t}$, the ARMA model is a tool for understanding and, perhaps, predicting future values in this series[27]. The model consists of two parts, an autoregressive (AR) part and a moving average (MA) part. The model is usually then referred to as the ARMA $(p, q)$ model where $p$ is the order of the autoregressive part and $q$ is the order of the moving average part (as defined below).

\subsubsection{Autoregressive model}

The notation $\operatorname{AR}(p)$ refers to the autoregressive model of order $p$. The $\operatorname{AR}(p)$ model is written

$$
X_{t}=c+\sum_{i=1}^{P} \rho_{i} X_{t}+\varepsilon_{t}
$$

Where, $\rho_{1}, \rho_{2} \ldots . \rho_{p}$ are the parameters of the model, $c$ is a constant and $\varepsilon_{t}$ is white noise. Sometimes the constant term is avoided.

\subsubsection{Moving average model}

The notation MA $(q)$ refers to the moving average series of order $q$ :

$$
X_{t}=\mu+\varepsilon_{t}+\sum_{i=1}^{q} \theta_{i} \varepsilon_{t-i}
$$

Where,

$\theta_{1}, \theta_{q}$ are the parameters of the model, $\mu$ is the expectation of $X_{t}$ (often assumed to equal 0 ), and the $\varepsilon_{t}, \varepsilon_{t-1}$

A time series $\left\{X_{t}\right\}$ is stationary and if for every $t$,

$X_{t}-\phi_{1} X_{t-1}-\ldots \ldots \ldots . \phi_{p} X_{t-p}=Z_{t}+\theta_{1} Z_{t-1}+\ldots \ldots . .+\theta_{q} Z_{t-q}$

Where, $\left\{Z_{t}\right\} \sim W N\left(0, \sigma^{2}\right)$ and the polynomials

$\left(1-\phi_{1} Z-\ldots \ldots \ldots-\phi_{p} Z^{p}\right)$ and $\left(1+\theta_{1} Z+\ldots \ldots .+\theta_{q} Z^{q}\right)$

have no common factors.

Where, $p$ and $q$ are respectively the AR and MA terms.

\subsection{Artificial Neural Network Models (ANN)}

For the Artificial Neural Network models, [18] stated that these models provide a great deal of promise in forecasting. We found them applied in several fields, electricity prices predication [19], in Hydrology [20] in Biology [21] etc the theoretical background of ANN is depicted in Fig. 1 ; the essential components that determine the ANNs are Architecture structure and learning algorithm. For the first component, we follow the Feed-forward back propagation network (as in Fig. 1).

\subsection{Fuzzy Time Series}

The FTS models are based on the fuzzy logic and fuzzy sets theory developed by [22], this method is considered as a support of decision making. Furthermore, the FTS doesn't require any prior assumptions for time series and model building, an advantage compared the classical methods (e.g. Box-Jenkins approach). Several statisticians have been contributed to develop this technique, including $[17,23,24,25,26,27]$. 


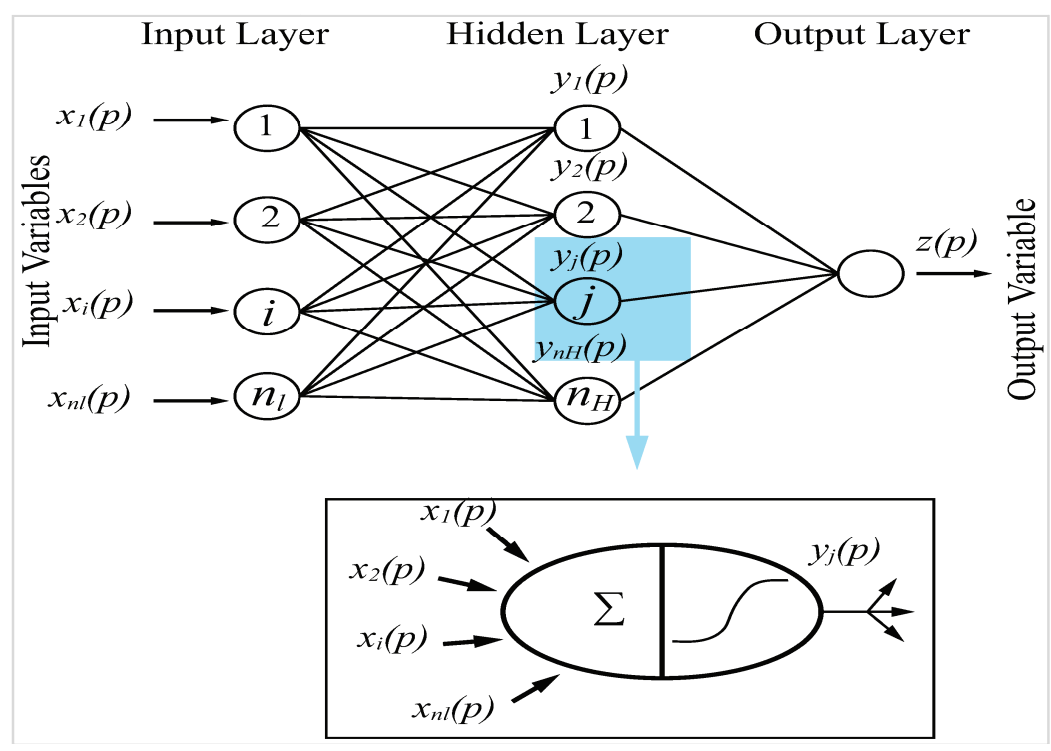

Fig. 1. Architecture structure of the Artificial Neural Network model

The theoretical steps to construct a fuzzy time series model are:

1. Determine the universe of discourse: which is the range of (or the interval) covering all data, the most used formula is: $\Omega=$ $\left[\operatorname{Min}\left(\mathrm{y}_{\mathrm{t}}\right)-\mathrm{d}_{1} ; \operatorname{Max}\left(\mathrm{y}_{\mathrm{t}}\right)+\mathrm{d}_{2}\right], \mathrm{d}_{1}$ and $\mathrm{d}_{2}$ are arbitrarily real numbers.

2. Definition of Fuzzy Sets: they are the subintervals of the universe of discourse; we work on the equal lengths of each subinterval; according to [23] there are no prior assumptions on determining how many linguistic variables to be fuzzy sets.

3. Fuzzification of the original data set: (convert the raw data (numbers) to linguistic form.

4. Definition of fuzzy logic relationships (state the relation among the fuzzy sets), where we define the fuzzy relation matrix.

5. Estimate the forecasted output and interpret the results.

In the next section, these two approaches have been applied on the real data set of Covid-19 in India represented by the new number of deaths and the new confirmed cases.

\section{RESULTS AND DISCUSSION}

The data source is from the World Health Organization (WHO) daily situation reports, (https://www.who.int/emergencies/diseases/novel -coronavirus-2019/situation-reports). We first, proceed to describe the data. Table 1 shows the summary statistics of the two time series, the number of observations covered under the period investigated (17 March to 01 July) is 107 for each. The range values for the two time series are $[0,507]$ and $[0,19906]$.

The coefficient of variation indicates that the dispersion is nearly the same for the new deaths and new confirmed cases time series over the study period. Rapid and onward changes in number of cases and number of deaths results such high $\mathrm{CV}$ percentage in both the parameters under consideration. According to the homogeneity test, we see that the change points for the two time series (New cases, new death) are the observations correspond on 2168 and 12564 new cases, and 28 and 247 new deaths. The positive value of skewness (0.796) which indiçâtes the probability of increasing in the new deaths.

Table 1. Summary statistics for the new death and new confirmed cases time series

\begin{tabular}{llllllllll}
\hline Variable & $\begin{array}{l}\text { Obs } \\
(\mathbf{N})\end{array}$ & Min & Max & Mean & S.D & $\begin{array}{l}\text { C.V } \\
(\%)\end{array}$ & Skwnes & Kurtosis & $\begin{array}{l}\text { JB statistics } \\
\left({ }^{* *}\right)\end{array}$ \\
\hline New_deaths & 107 & 0 & 507 & 147 & 141 & 95.9 & 0.796 & 2.362 & 13.11 \\
New_cases & 107 & 0 & 19906 & 5471 & 5580 & 102.2 & 0.976 & 2.892 & 17.05 \\
\hline \multicolumn{6}{c}{ Notes. JB: Jark-bera test for normality, $\left.{ }^{* *}\right)$ indicates statistically significant for $p$-value $<0.001$}
\end{tabular}




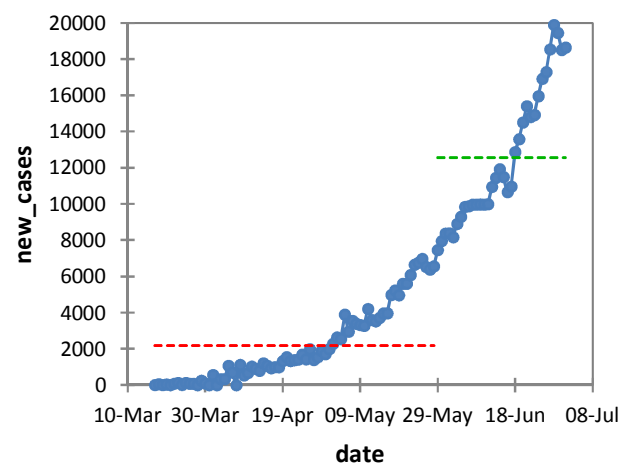

\begin{tabular}{ll|}
$\longrightarrow-$ new_cases & $-\cdots--$ mu1 $=2168$ \\
$\cdots--m$ mu2 $=12564$ &
\end{tabular}

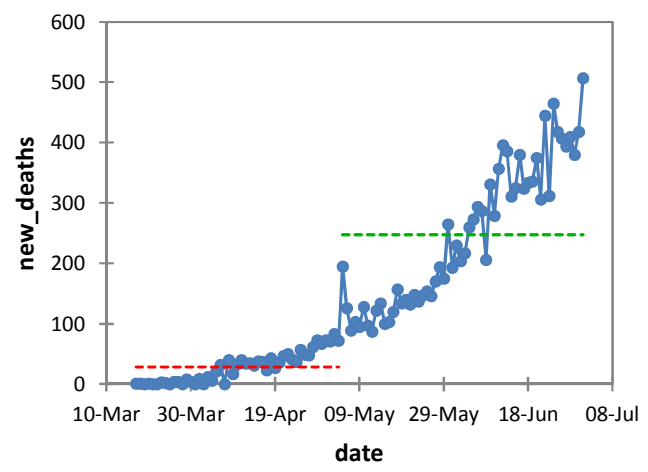

$\longrightarrow$ new_deaths $\quad$ - $-\cdots--$ mu1 $=28$
$\ldots-\cdots$ mu2 $=247,552$

Fig. 2. Dynamics and structural changes of the new cases and new death time series; mu1 and mu2 are (respectively) the average (mean) number of cases (deaths or confirmed cases) for the first regime in red (or cycle) and second regime in green

Table 2. Estimation of Model parameters

\begin{tabular}{lllllll}
\hline Source & Value & $\begin{array}{l}\text { Standard } \\
\text { error }\end{array}$ & $\mathbf{t}$ & $\operatorname{Pr}>|\mathbf{t}|$ & $\begin{array}{l}\text { Lower bound } \\
\mathbf{( 9 5 \% )}\end{array}$ & $\begin{array}{l}\text { Upper bound } \\
\mathbf{( 9 5 \% )}\end{array}$ \\
\hline Intercept & 13.2921 & 4.9170 & 2.7033 & 0.0080 & 3.5425 & 23.0416 \\
Newcase & 0.0245 & 0.0006 & 38.7830 & $<0,0001$ & 0.0232 & 0.0257 \\
\hline
\end{tabular}

Note: the coefficient of determination $R^{2}=0.937$, the $p$-value of the F-statistics is $<0.005$, we accept this model

For normality assumption, the kurtosis is nearly than in a normal distribution, this assumption is an important one to fit the ARIMA models; in contrast the skewness measures (0.79 and 0.97) for both new cases and new deaths time series indicate data are skewed right in Fig. 2.

\subsection{What about the Correlation between Dynamics in Confirmed New Cases and Specific New Deaths?}

As logical and biological facts, there is a relationship between the number of the confirmed new cases and numbers of death caused by a specific disease. Statistically, the functional form of this relationship varies from a disease (or a pandemic) to other. In case of COVID-19 data from India, we estimate the cross-correlation function (CCF), which is a generalization of simple correlation coefficient between these two variables. The results are shown below,

The CCF depicts a positive and symmetric (compared to simple correlation at lag 0) correlation through the lags $[-20,-19, \ldots, 0, \ldots, 19,20]$. When we jump to the causal inference, we run a simple linear regression model to estimate the effect of the new cases (NC) variable on the new number of deaths (ND), the estimation results are summarized in Table2.

The utility of such modeling reside in predictive the future death cases and the imputation of missing observations for the two time series; for more reliability and result accuracy, we can simply generalize the estimation of this relationship for other countries. It indicates that lag regression relationship between new total cases and new deaths.

\subsection{Time Series Modeling and Forecasting}

According to the partial autocorrelation functions (PACF), which has been considered important in data analysis and modeling, especially to identify the lag extending in Box-Jenkins approach, to indentify the stationary of data set. From Fig. 3, the new cases time series on day $(t)$ depends only and strongly with the past days (t-1) confirmed new cases. In contrast, the dependence structure of the new death time series is featured by a positive multi-lagged dependence (three days). 


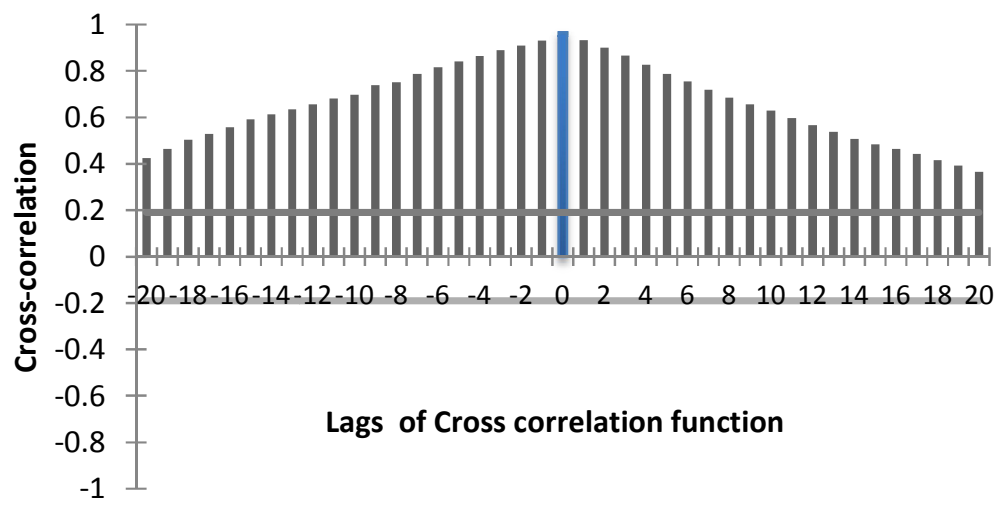

Fig. 3. Displays the cross correlations from both positive and negative lags. The value at lag 0 is the simple correlation between these two variables, it equals 0.9668

Table 3. Estimation accuracy measures for the three methods

\begin{tabular}{llllll}
\hline Time Series & Method & ME & RMSE & MAE & MASE \\
\hline New Cases & FTS & -641.1 & 917.6 & 773.9 & 1.723 \\
& ARIMA(3,2,3) & 62.41 & 436.55 & 34.97 & 0.843 \\
\hline & ANN & $\mathbf{1 9 . 2 2}$ & $\mathbf{3 8 . 2 2}$ & $\mathbf{2 3 . 1 2}$ & $\mathbf{0 . 5 6 4}$ \\
\hline New Deaths & FTS & -14.55 & 66.86 & 39.8 & 1.891 \\
& ARIMA $(1,1,1)$ & -0.141 & 31.08 & 21.10 & 0.927 \\
\hline \multicolumn{5}{c}{ Notes. The optimal ARIMA models have been selected according to the information criterion: BIC and AIC }
\end{tabular}

Table 4. Prediction of confirmed new cases and new deaths in India for the period (08-07 to 1407 2020)

\begin{tabular}{lllll}
\hline Time series & Date & FTS & ANN & ARIMA \\
\hline New cases & $08-07-2020$ & 21085 & 22458 & 21849 \\
& $09-07-2020$ & 20038 & 22664 & 22537 \\
& $10-07-2020$ & 19245 & 22870 & 24224 \\
& $11-07-2020$ & 18977 & 23076 & 26595 \\
& $12-07-2020$ & 19583 & 23282 & 27840 \\
& $13-07-2020$ & 20665 & 23488 & 27368 \\
& $14-07-2020$ & 21743 & 23694 & 26405 \\
\hline New deaths & $08-07-2020$ & 505 & 480 & 457 \\
& $09-07-2020$ & 534 & 505 & 456 \\
& $10-07-2020$ & 558 & 492 & 462 \\
& $11-07-2020$ & 580 & 496 & 466 \\
& $12-07-2020$ & 599 & 501 & 470 \\
& $13-07-2020$ & 618 & 508 & 474 \\
& $14-07-2020$ & 636 & 511 & 478 \\
\hline
\end{tabular}

According to fitting adequacy for both new cases and new deaths time series, we see clearly from Table3 that the ARIMA model fit better the data compared with Fuzzy time series models.

Table 4 and Fig. 4 depicts the forecast results for the nearest future of virus spread in India measured by the new cases and new deaths dynamics over the last 3 months. We stated that the three statistical methods provide us nearly the same expected trajectory of the virus in India. The common feature is a positive dynamics especially in term of daily new deaths caused by this virus, where the ANN models seem to expect a speed dynamic compared with other two methods (FTS and ARIMA). 
Mishra et al.; ARRB, 35(9): 46-54, 2020; Article no.ARRB.60216
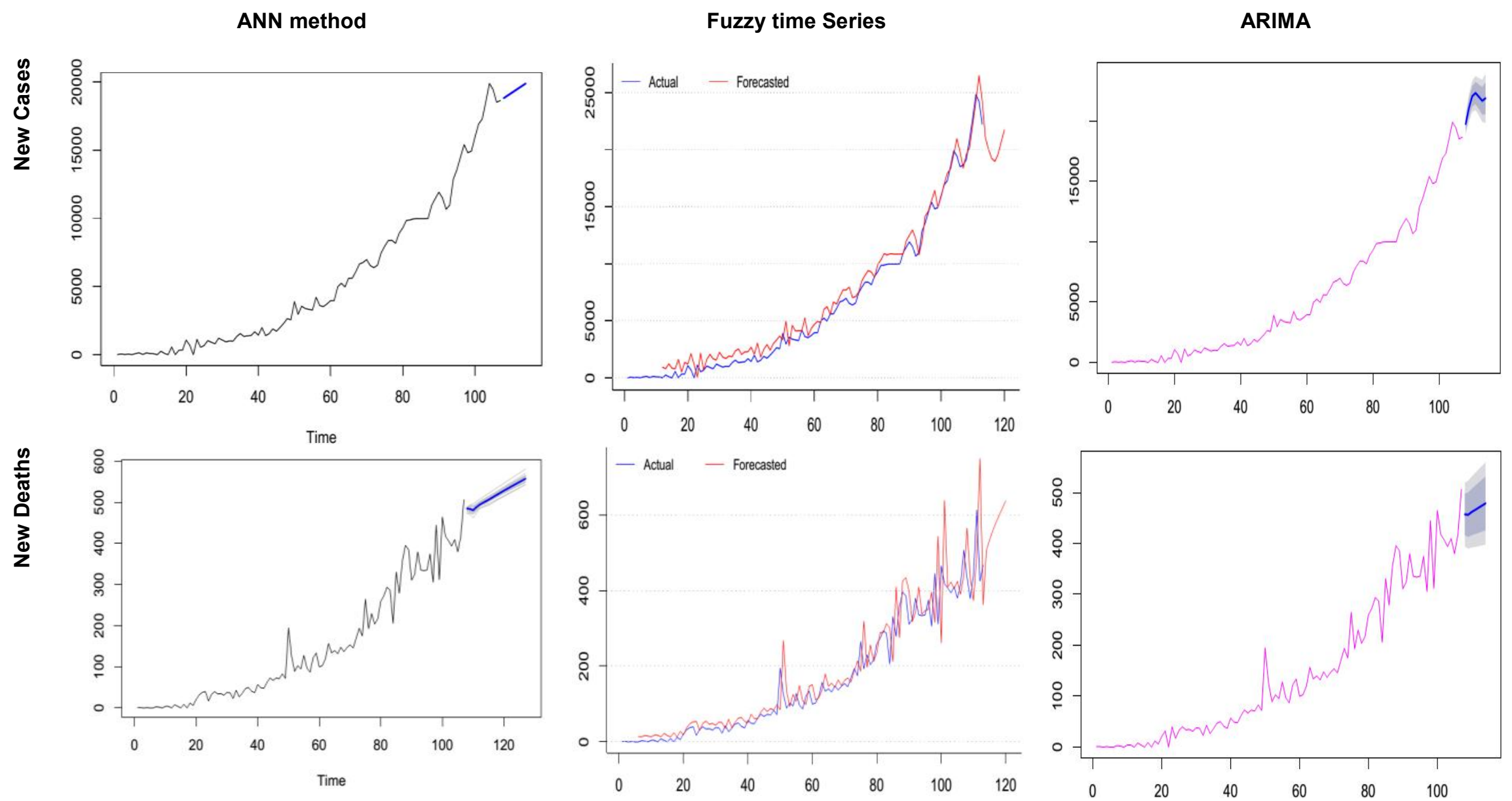

Fig. 4. Plots forecasts results for new cases and new deaths time series by the three methods 


\section{CONCLUSION}

This paper deals with modeling and forecasting for the short-term trajectory of the COVID-19 in India, where the Artificial Neural Network model, Fuzzy Time Series and Box-jenkins approaches have been applied on a 4-month data of the new cases and new deaths. Also, in the last four months, India has deployed lot of medical facilities due to death rate decreased over the time. The results indicate and predict a upwards urge in the spread of the virus, especially in terms of deaths over the next weeks. For models selections, the ARIMA and FTS are found more appropriate to forecast the virus trajectories.

\section{COMPETING INTERESTS}

Authors have declared that no competing interests exist.

\section{REFERENCES}

1. Chen Y, Liu Q, Guo D. Emerging coronaviruses: Genome structure, replication, andpathogenesis. J Med Virol; 2020.

2. Paules $\mathrm{Cl}$, Marston HD, Fauci AS.Coronavirus infections-More than just thecommon cold. JAMA - J Am Med Assoc; 2020.

3. World Health Organistation.Coronavirus disease 2019 (COVID-19) Situation Report $-181 ; 2020$.

4. Fanelli D, Piazza F. Analysis and forecast of COVID-19 spreading in China, Italy and France. Chaos, Solitons \& Fractals. 2020;134:109761.

5. Chimmula VKR, Zhang L. Time series forecasting of COVID-19 transmission in Canada using LSTM networks. Chaos, Solitons \& Fractals. 2020;109864.

6. Malavika B, Marimuthu S, Joy M, Nadaraj A, Asirvatham ES, Jeyaseelan L. Forecasting COVID-19 epidemic in India and high incidence states usingSIR and logistic growth models. Clinical Epidemiology and Global Health; 2020.

7. Petropoulos F, Makridakis S. Forecasting the novel coronavirus COVID-19. PloS one. 2020;15(3):0231236.

8. Alzahrani SI, Aljamaan IA, Al-Fakih EA. Forecasting the Spread of the COVID-19 Pandemic in Saudi Arabia Using ARIMA Prediction Model Under Current Public Health Interventions. Journal of Infection and Public Health; 2020.
9. Rustam F, Reshi AA, Mehmood A, Ullah S, On B, Aslam W, Choi GS. COVID-19 Future Forecasting Using Supervised Machine Learning Models. IEEE Access; 2020.

10. Sujath R, Chatterjee JM, Hassanien AE. A machine learning forecasting model for COVID-19 pandemic in India. Stochastic Environmental Research and Risk Assessment. 2020;1.

11. Gardner Jr, ES. Exponential smoothing: The state of the art. Journal of forecasting. 1985;4(1):1-28.

12. Box G, Jenkins Gwilym. Time Series Analysis: Forecasting and Control. San Francisco: Holden-Day; 1970.

13. Xie $Y$, Zhang $Y, Y e ~ Z$. Short-term traffic volume forecasting using Kalman filter with discrete wavelet decomposition. Computer-Aided Civil and Infrastructure Engineering. 2007;22(5):326-334.

14. Zhang G, Patuwo BE, Hu MY. Forecasting with artificial neural networks. The state of the art. International journal of forecasting. 1998;14(1):35-62.

15. Khashei $M$, Bijari $M$. An artificial neural network ( $p, d, q)$ model for timeseries forecasting. Expert Systems with applications. 2010;37(1):479-489.

16. Abbasov AM, Mamedova $\mathrm{MH}$. Application of fuzzy time series to population forecasting, Proceedings of 8th Symposium on Information Technology in Urban and Spatial Planning, Vienna University of Technology, February 25March1. 2003;545-552.

17. Singh SR. A computational method of forecasting based on fuzzy time series. Mathematics and Computers in Simulation. 2008;79:539-554.

18. Zhang G, Patuwo BE, Hu MY. Forecasting with artificial neural networks:: The state of the art. International journal of forecasting. 1998;14(1):35-62.

19. Mandal P, Senjyu T, Funabashi T. Neural network models to predict short-term electricity prices and loads. In 2005 IEEE International Conference on Industrial Technology. 2005;164-169.

20. Jain A, Kumar AM. Hybrid neural network models for hydrologic time series forecasting. Applied Soft Computing. 2007;7(2):585-592.

21. Price RK, Spitznagel EL, Downey TJ, Meyer DJ, Risk NK, El-Ghazzawy OG. Applying artificial neural network models to 
clinical decision making. Psychological Assessment. 2000;12(1):40.

22. Zadeh LA. Fuzzy sets. Information and Control. 1965;8:338-353.

23. SongQ, Chissom BS. Forecasting enrollments with fuzzy time seriespart 1. Fuzzy Sets and Systems. 1993;54:1-9.

24. Chen SM, Hsu CC. A New method to forecast enrollments using fuzzy time series. International Journal of Applied Science and Engineering. 2004;12:234244.
25. Huarng $H$. Huarng models of fuzzy time series for forecasting. Fuzzy Sets and Systems. 2001;123:369-386.

26. Jiang PQ, Dong P, Li Lian L.A novel highorder weighted fuzzy time series model and its application in nonlinear time series prediction, Appl. Soft Comput. 2017;55:4462

27. Mishra P, Fatih C, Niranjan HK, TiwariS, Devi M, Dubey A. Modelling and Forecasting of Milk Production in Chhattisgarh and India. Indian Journal of Animal Research. 2020;54 (7):912-917.

(c) 2020 Mishra et al.; This is an Open Access article distributed under the terms of the Creative Commons Attribution License (http://creativecommons.org/licenses/by/4.0), which permits unrestricted use, distribution, and reproduction in any medium, provided the original work is properly cited.

Peer-review history:

The peer review history for this paper can be accessed here: http://www.sdiarticle4.com/review-history/60216 